\title{
Interactions between wear and corrosion on cast and sintered Ti-12Nb alloy in comparison with the commercial Ti-6Al-4V alloy
}

\author{
I. Çaha $^{\mathrm{a} * *}$, A.C. Alves ${ }^{\mathrm{a}}$, C. Chirico ${ }^{\mathrm{b}}$, S.A. Tsipas ${ }^{\mathrm{b}, \mathrm{f}}$, I.R. Rodrigues ${ }^{\mathrm{d}, \mathrm{e}}$, A.M.P. Pinto ${ }^{\mathrm{a}, \mathrm{c}}$, \\ C.R. Grandini ${ }^{\mathrm{d}, \mathrm{e}}$, L.A. Rocha ${ }^{\mathrm{d}, \mathrm{e}}$, E. Gordo ${ }^{\mathrm{b}, \mathrm{f}}$, F. Toptan ${ }^{\mathrm{a}, \mathrm{e}}$ \\ ${ }^{\text {a }}$ CMEMS-UMinho - Center for MicroElectroMechanical Systems, Universidade do Minho, Azurém, 4800-058, Guimarães, Portugal \\ ${ }^{\mathrm{b}}$ Universidad Carlos III de Madrid, Avda. Universidad, 30, 28911, Leganés, Spain \\ ${ }^{\mathrm{c}}$ Universidade do Minho, Dept. Eng. Mecânica, Azurém, 4800-058, Guimarães, Portugal \\ ${ }^{\mathrm{d}}$ UNESP-Univ. Estadual Paulista, Faculdade de Ciências de Bauru, Dep. Física, 17033-360 Bauru, SP, Brazil \\ ${ }^{\mathrm{e}} \mathrm{IBTN} / \mathrm{Br}$ - Brazilan Branch of the Institute of Biomaterials, Tribocorrosion and Nanomedicine, 17033-360, Bauru, SP, Brazil \\ f Instituto "Álvaro Alonso Barba", 30, 28911, Leganés, Madrid, Spain
}

A R T I C L E I N F O

\section{Keywords:}

Titanium alloys

Casting

Powder metallurgy

Corrosion

Tribocorrosion

\begin{abstract}
A B S T R A C T
This work investigates the corrosion and tribocorrosion behavior of $\alpha+\beta \mathrm{Ti}-12 \mathrm{Nb}$ alloy processed by casting and sintering, in $9 \mathrm{~g} / \mathrm{l} \mathrm{NaCl}$ solution at body temperature, and compares the results with the commercial Ti-6Al$4 \mathrm{~V}$ alloy. Different electrochemical techniques were used to access the corrosion behavior. Tribocorrosion behavior was studied at open circuit potential under continuous and intermittent sliding, and at anodic potentiostatic condition under continuous sliding. Results revealed that Ti-12Nb alloys presented similar tribocorrosion behavior although the sintered one exhibited a better corrosion behavior. Nevertheless, Ti- $6 \mathrm{Al}-4 \mathrm{~V}$ presented better overall degradation resistance than both Ti-12Nb alloys.
\end{abstract}

\section{Introduction}

Titanium alloys are chosen for biomedical applications due to their superior corrosion resistance, excellent mechanical strength, and good biocompatibility. Among these alloys, the $\alpha+\beta$ Ti-6Al-4 V alloy has been extensively used in biomedical implants owing to the combination of unique physical and mechanical properties. However, considerable controversy has been raised due to possible long term adverse effects of released $\mathrm{Al}$ and $\mathrm{V}$ ions from Ti-6Al-4 V alloy [1]. Also, its Young's modulus $(\sim 110 \mathrm{GPa})$ is much higher than that of human bone $(\sim 20 \mathrm{GPa})[2]$. The mismatch in Young's modulus may lead to inhomogeneous transfer of stress between the implant and bone resulting in resorption of bone (stress shielding phenomenon) [3].

Ti-Nb based alloys have attracted attention due to their lower Young's moduli [4], good corrosion resistance [5], and superior biocompatibility [6]. Yilmaz et al. [7] presented that the good corrosion resistance of $\mathrm{Ti}-\mathrm{Nb}$ alloys over $\mathrm{Ti}$ has been governed by the stable behavior of $\mathrm{Nb}_{2} \mathrm{O}_{5}$ oxide. In addition to the effect of the alloying elements, the microstructure also has a significant effect on corrosion behavior [8]. Sintered alloys usually have higher porosity as compared to the cast alloys, that can also influence the corrosion behavior [9].

Some biomedical applications such as hip prosthesis constitute a tribocorrosion system due to the presence of relative movements between bone and implant, and between the modular parts of the prosthesis during the movement of the human body. The release of metallic ions due to corrosion and wear can cause osteolysis and eventually implant failure [10]. Corrosion and tribocorrosion behavior of $\mathrm{Ti}$ and Ti-6Al-4 V have been well studied in different conditions. For instance, Dimah et al. [11] studied the corrosion and tribocorrosion behavior of cp-Ti, Ti-6Al-4 V, and Ti-6Al-4V-ELI in phosphate buffered solution (PBS) with and without the addition of bovine serum albumin. It was reported that the produced wear debris was affected by the testing solution. The authors also studied the influence of repassivation rate and passive film growth on the tribocorrosion behavior of the Ti-6Al4V-ELI alloy through intermittent sliding tests and it was found that the wear rate increased with increasing of the resting time between the sliding cycles due to the growth of the passive films during the pause periods. On the other hand, regarding the effect of the processing route, Licausi et al. [12] investigated the corrosion and tribocorrosion behavior of Ti-6Al-4 $\mathrm{V}$ alloy processed by either casting or powder metallurgy $(\mathrm{P} / \mathrm{M})$, in artificial saliva (with or without the addition of fluoride) and commercial mouth wash. Although the results were influenced by the testing solutions, as general, the authors reported better tribocorrosion behavior for the sintered alloys.

\footnotetext{
* Corresponding author.

E-mail address: ihsancaha@gmail.com (I. Çaha).
} 
While its toxicity and high Young's modulus is still a concern, the $\alpha+\beta$ type Ti-6Al-4 V alloy is still the dominant Ti-based implant material. Although vanadium-free Ti-6Al-7Nb alloy was developed for biomedical applications, especially for hip prothesis [13], this alloy has still higher Young's modulus (110 GPa) [13] and still include Al, that is suspected to be associated with Alzheimer's disease [1,14]. Recently, several studies reported lower wear resistance for low Young's modulus and non-toxic $\beta$ type Ti alloys tested in $9 \mathrm{~g} / \mathrm{l} \mathrm{NaCl}$ solution [15], Ringer's solution [16], simulated body solution [17], and under dry sliding condition [18], mainly due to the low strain hardening behavior of the $\beta$ phase. Further understanding is needed on the tribocorrosion behavior of non-toxic and low Young's modulus Ti alloys being developed as an alternative to Ti-6Al-4 V for load-bearing implant applications. Accordingly, this study aims to process the $\alpha+\beta$ Ti-12Nb alloy either by casting and $\mathrm{P} / \mathrm{M}$ and to investigate the influence of the processing method on the degradation behavior in comparison with the commercial Ti-6Al-4 V alloy.

\section{Experimental procedure}

\subsection{Materials and processing}

The raw materials used to produce cast Ti-12Nb alloy were Ti (99.7 $\%$ purity, Sandinox Biometais, Brazil) and $\mathrm{Nb}$ (99.8 \% purity, Brazilian Metallurgy and Mining Company), whereas $\mathrm{TiH}_{2}\left(\mathrm{GfE}, \mathrm{D}_{50}: 27 \mu \mathrm{m}\right)$ and $\mathrm{Nb}$ (Alfa Aesar, $\mathrm{D}_{50}: 15 \mu \mathrm{m}$ ) powders were used to produce the sintered Ti-12Nb alloy. Regarding the cast alloy, the raw metals were arc-melted on a water-cooled copper crucible under an argon inert atmosphere with a non-consumable tungsten electrode. The ingots were re-melted several times then heat treated at $1000{ }^{\circ} \mathrm{C}$ for $24 \mathrm{~h}$ in an ultra-vacuum furnace for homogenization. Afterwards, the ingot was submitted to a hot-rolling treatment carried out at $900{ }^{\circ} \mathrm{C}$ and, finally, another heat treatment at $1000{ }^{\circ} \mathrm{C}$ for $24 \mathrm{~h}$ in a vacuum to relieve the residual stress during the machining procedure (complete details of the processing are given elsewhere [15]). In the case of the alloy produced by $\mathrm{P} / \mathrm{M}, \mathrm{TiH}_{2}$ and $\mathrm{Nb}$ powders were homogenized by mixing for $1 \mathrm{~h}$ in a Turbula ${ }^{\circledR}$ multidirectional mixer. Green compacts $(16 \mathrm{~mm}$ in diameter and about 3-4 $\mathrm{mm}$ in thickness) were acquired under $700 \mathrm{MPa}$ pressure using zinc stearate as a die wall lubricant. The samples were sintered in a tubular furnace under a high vacuum $\left(10^{-5}\right.$ mbar) by holding $4 \mathrm{~h}$ at $1250{ }^{\circ} \mathrm{C}$ (complete details of the processing are given elsewhere [19]). Commercial Ti-6Al-4 V alloy (VSMPO Tirus, US, ASTM B348, Grade 5) was used as a control group.

\subsection{Characterization of alloys}

The microstructure of the alloys was characterized by optical microscopy (Leica, DM2500) after preparing the samples by grinding down to 1200 grit $\mathrm{SiC}$ paper, then polished with colloidal silica suspension $(0.02 \mu \mathrm{m}$ particle size), and etched by Kroll's reagent ( $3 \mathrm{~mL} \mathrm{HF}$, $6 \mathrm{~mL} \mathrm{HNO}_{3}$, and $91 \mathrm{~mL} \mathrm{H}_{2} \mathrm{O}$ ). The structural characterization of Ti$12 \mathrm{Nb}$ alloys was performed by X-ray diffraction (XRD, DMAX-2100, Rigaku). The phase percentages were calculated with the Rietveld refinement method by using Topas-Academic software. Microhardness of the alloys was determined by 10 indentations with a load of $4.90 \mathrm{~N}$ $(0.50 \mathrm{kgf})$ during $30 \mathrm{~s}$. The Young's modulus of the cast and sintered Ti$12 \mathrm{Nb}$ alloys was obtained from 10 measurements by using a dynamic manner with the Sonelastic ${ }^{\circledR}$ equipment (ATCP) based on ASTM-E1876 standard, using the technique of excitation by impulse, with the samples placed in flexural vibration. Roughness of the alloys was taken by a non-contact profilometer (Veeco, Dektak 150).

\subsection{Corrosion tests}

The corrosion behavior was analyzed through electrochemical impedance spectroscopy (EIS), and potentiodynamic polarization measurements in saline $(9 \mathrm{~g} / 1 \mathrm{NaCl})$ solution at body temperature $\left(37 \pm 2{ }^{\circ} \mathrm{C}\right)$ using Gamry Potentiostat/Galvanostat/ZRA (model Reference- $600+$ ). In order to observe the stabilization of the native oxide film formed on the sample surfaces, OCP was monitored until obtaining $\Delta E<60 \mathrm{mV} / \mathrm{h}$ [20]. Afterwards, EIS tests were carried out with scanning between $10^{-2}$ to $10^{5} \mathrm{~Hz}$ with 7 points per frequency decade with $10 \mathrm{mV}$ of the amplitude of a sinusoidal signal. The potentiodynamic polarization scans were studied from $-0.25 \mathrm{~V}_{\mathrm{OCP}}$ to 1.5 $\mathrm{V}_{\mathrm{SCE}}$ with a scan rate of $0.5 \mathrm{mV} \mathrm{s}^{-1}$. All electrochemical tests were performed in a three-electrode cell with $180 \mathrm{~mL}$ of the electrolyte where samples were used as the working electrode (WE), with an exposed area of $0.38 \mathrm{~cm}^{2}$, a Pt electrode was used as the counter electrode (CE), and a saturated calomel electrode (SCE) was used as the reference electrode (RE).

\subsection{Tribocorrosion tests}

Tribocorrosion tests were performed in an electrochemical cell connected to a reciprocating ball-on-plate tribometer (CETR-UMT-2). The experiments were performed in saline $(9 \mathrm{~g} / \mathrm{l} \mathrm{NaCl})$ solution at $37 \pm 2{ }^{\circ} \mathrm{C}$ temperature using Gamry Potentiostat/Galvanostat/ZRA (model Reference 600) with the same electrode configurations used in the electrochemical tests. A $10 \mathrm{~mm}$ diameter alumina ball (Ceratec) was used as the counter-body. The tests were carried out both under continuous and intermittent sliding at OCP, and under continuous sliding at an anodic applied potential (AP) of $+0.5 \mathrm{~V}_{\mathrm{SCE}}$ (Fig. 1). Intermittent tests were included in order to provide an extra information on the mechanism of the periodic removal and re-growth of surface oxide film [21]. During intermittent sliding, linear polarization (LPR) scans were performed $3 \mathrm{~min}$ before each sliding step, and $7 \mathrm{~min}$ after the final sliding step, at $\pm 20 \mathrm{mV}_{\mathrm{OCP}}$ with $0.5 \mathrm{mVs}^{-1}$ scanning rate, in order to investigate the effect of sliding damage on the polarization resistance $\left(R_{p}\right.$, extracted from LPR tests by using Gamry Echem Analyst software version 7.1). Each 6 sliding steps were employed for $5 \mathrm{~min}$, giving $30 \mathrm{~min}$ of total sliding time such as continuous sliding. All tribocorrosion tests were performed at $1 \mathrm{~Hz}$ of frequency, $3 \mathrm{~mm}$ of amplitude, and $1 \mathrm{~N}$ of normal load (corresponds to 0.41 and $0.37 \mathrm{GPa}$ maximum Hertzian contact pressure for Ti-6Al-4 V and both Ti-12Nb alloys, respectively [22]). After each test, samples were cleaned in propanol and distilled water in ultrasonic bath for $10 \mathrm{~min}$ and $5 \mathrm{~min}$, respectively, and the surfaces were analyzed by using FEG-SEM/EDS (FEI Nova 200/ EDAX). Wear volume loss was calculated for all conditions following the method described before by Doni et al. [23], through wear track profiles taken by a profilometer (Veeco, Dektak 150).

\subsection{Statistical analysis}

The results are presented as the average \pm standard deviation values from tests run in triplicates on three independent samples. Statistical analysis was evaluated by one-way ANOVA followed by Tukey's test for multiple comparisons, considering $p<0.05$ as significant.

\section{Results}

\subsection{Physical and structural properties}

The microstructures and XRD spectra of the Ti-6Al-4 V and Ti-12Nb alloys are given in Fig. 2. The optical microscope images evidence microstructures constituted by a mixture of $\alpha+\beta$ phases for all alloys. The Ti-6Al-4 V alloy showed the small-sized homogenous distribution of grains with equiaxial $\alpha$ phase and $\beta$ phase in grain boundaries (Fig. 2a). The light-colored (Nb rich area) and dark-colored (Ti-rich area) regions on Ti-Nb alloys represent $\beta$ and $\alpha$ phases, respectively. The cast (Fig. 2b) and sintered (Fig. 2c) Ti-12Nb alloys are composed of lamellar $\alpha+\beta$ phases, however, the cast Ti-12Nb alloy showed a 

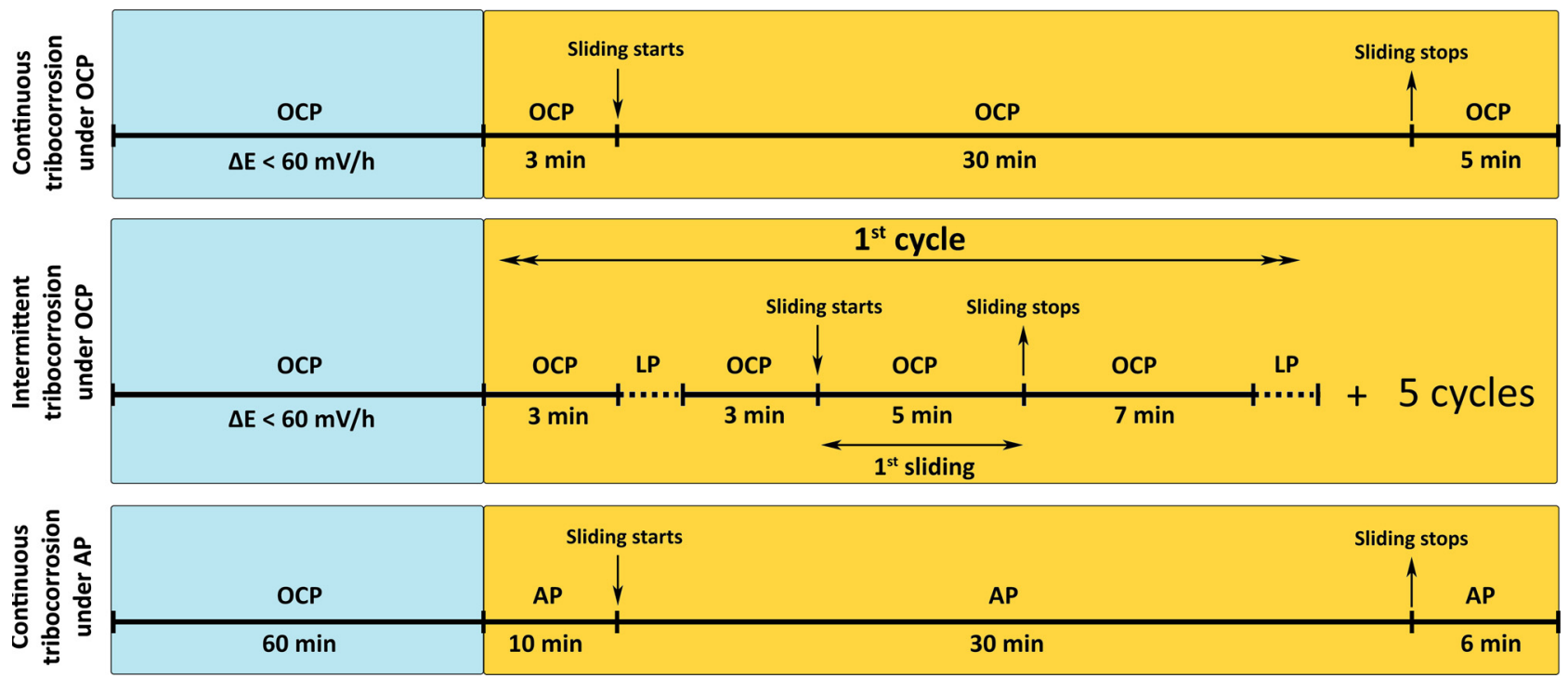

Fig. 1. Schematic representation of the tribocorrosion protocol.

thicker and relatively inhomogeneously distributed $\beta$ phase, that may be explained by the hot deformation during processing resulting in the change of microstructures and phase transformations on two-phase titanium alloys as pointed by Banumathy et al. [24]. The sintered Ti$12 \mathrm{Nb}$ alloy exhibited smaller grain size and a more homogenous distribution of lamellar $\alpha$ and $\beta$ phases with the presence of small pores. The XRD patterns of the Ti-12Nb alloys were composed of $\alpha$ (ICDD $00-044-1294$ ) and $\beta$ (ICDD 00-044-1288) phases which are in accordance with the observed microstructure. The phase percentages of the cast and the sintered alloys were $81 \% \alpha, 19 \% \beta$ and $84 \% \alpha, 16 \%$ $\beta$, respectively. These changes in the microstructure affected the mechanical properties (Table 1 ). The sintered Ti-12Nb alloy was harder than the cast one, whereas the commercial Ti-6Al-4 V was significantly
Table 1

Hardness, Young's modulus and $\mathrm{R}_{\mathrm{a}}$ values.

\begin{tabular}{llll}
\hline Samples & $\begin{array}{l}\text { Hardness } \\
\left(\mathrm{HV}_{0.5}\right)\end{array}$ & $\begin{array}{l}\text { Young's Modulus } \\
(\mathrm{GPa})\end{array}$ & $\begin{array}{l}\text { Average surface } \\
\text { roughness- } \mathrm{R}_{\mathrm{a}}(\mu \mathrm{m})\end{array}$ \\
\hline Ti-6Al-4V & $350 \pm 3$ & $112[1]$ & $0.19 \pm 0.02$ \\
$\begin{array}{l}\text { Cast Ti-12Nb } \\
\text { sintered Ti- } \\
\quad 252 \pm 4\end{array}$ & $267 \pm 5$ & $94.6 \pm 0.4$ & $0.25 \pm 0.02$ \\
\multicolumn{1}{c}{ 12Nb } & & & $0.27 \pm 0.01$ \\
\hline
\end{tabular}

harder than the both Ti-Nb alloys $(p<0.05)$. Young's modulus of the sintered alloy was slightly higher than that of the cast one that may be linked to the relatively lower concentration of $\beta$ phase and smaller grains obtained on the sintered alloy. Even though, the values were
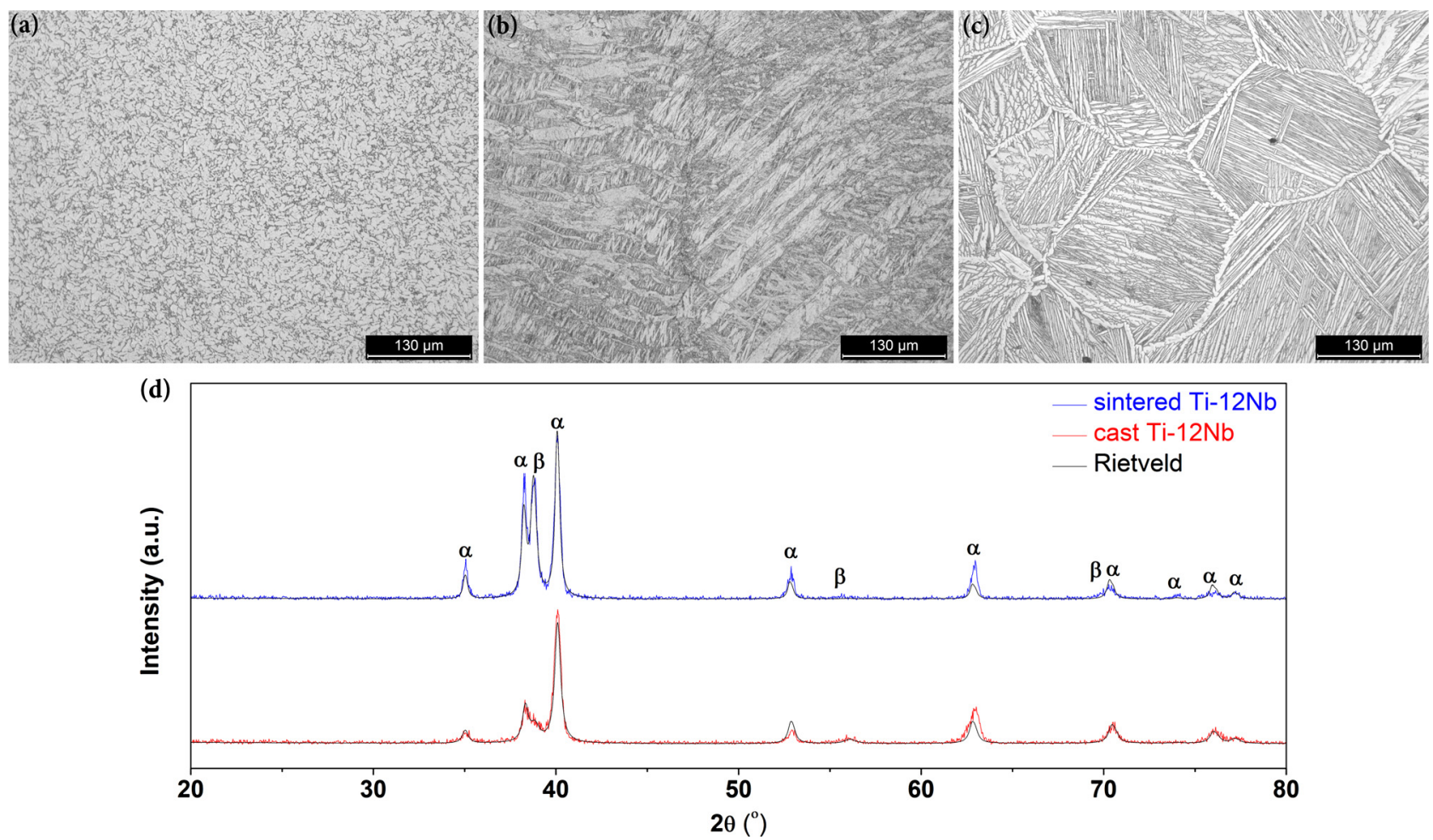

Fig. 2. Microstructural images of a) Ti-6Al-4 V, b) Cast Ti-12Nb, and c) sintered Ti-12Nb alloys, and d) XRD patterns of the cast and sintered Ti-12-Nb alloys. 

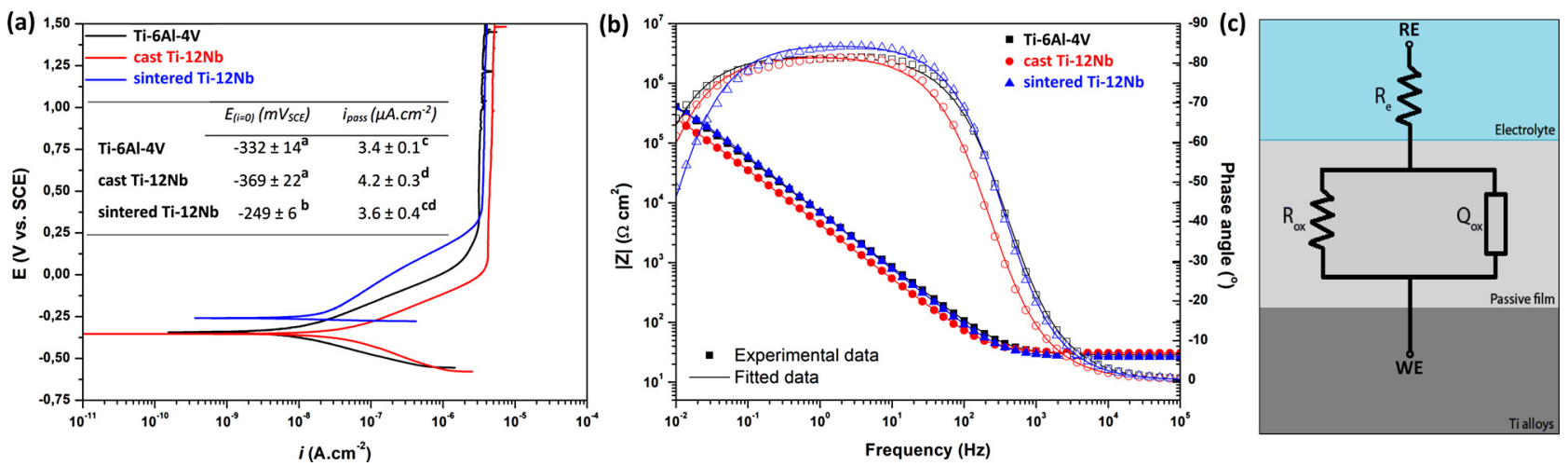

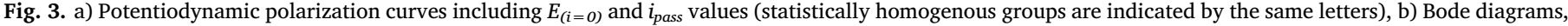
and (c) representative EEC for fitted EIS data.

noticeably lower than that of the commercial Ti-6Al-4 V alloy, that is reported in the literature as $112 \mathrm{GPa}$ [1]. The $\mathrm{R}_{\mathrm{a}}$ value of the Ti-6Al-4 V was considerably lower than the both Ti-12Nb alloys, while the average value of sintered alloy was slightly higher than the cast alloy.

\subsection{Corrosion results}

Representative results of the electrochemical tests are given in Fig. 3. Regarding the potentiodynamic polarization curves (Fig. 3a), all samples presented passivation plateau started at $-41 \pm 6 \mathrm{mV}_{\mathrm{SCE}}$, $200 \pm 103 \mathrm{mV}_{\mathrm{SCE}}$, and $374 \pm 29 \mathrm{mV}_{\mathrm{SCE}}$ for the cast Ti-12Nb, Ti-6Al$4 \mathrm{~V}$, and sintered Ti-12Nb, respectively. The sintered Ti-12Nb presented statistically significant higher corrosion potential $\left(\mathrm{E}_{(\mathrm{i}=0)}\right)$ than the other alloys. While the cast Ti-12Nb sample presented higher passivation current density $\left(i_{\text {pass }}\right)$ than the other alloys, the statistically significant difference was only observed with the Ti-6Al-4 V alloy $(p<0.05)$.

In order to obtain further information on the protective character of passive films formed on the samples, EIS was carried out. Representative Bode diagrams are shown in Fig. 3b. The fitted EIS parameters for tested alloys were computed by Gamry Echem Analyst software (version 7.05) and summarized in Table 2. The quality of the suggested electrical equivalent circuit (EEC, Fig. 3c) was evaluated through the goodness of fitting where the EEC presented values below $10^{-4}$. The EEC included $R_{e}, R_{o x}$, and $Q_{o x}$ corresponding to the resistance of the electrolyte, the resistance of the oxide layer, and a constant phase angle element (CPE) of the oxide layer, respectively. The CPE indicating a non-ideal behavior of capacitive elements due to surface heterogeneity results from impurities, roughness, and dislocations. The impedance of CPE is expressed as $Z_{C P E}=\left[Y_{0}(j w)^{n}\right]^{-1}$, where $Y_{0}$ is the CPE constant, $w$ is the angular frequency in $\mathrm{rad} / \mathrm{s}, j^{2}=-1$ is the imaginary number, and $n$ is the exponential factor, $-1 \leq n \leq 1$. When the $n$ value is 1,0 , and -1 , the CPE response is an ideal capacitor, a resistor, and an inductor, respectively. The $n$ value is associated with the roughness of the surface and its heterogeneities [25]. The capacitance $\left(\mathrm{C}_{\mathrm{ox}}\right)$ values of a single oxide layer parallel to its resistance result from its dielectric properties converted from $Q_{o x}$ values through Eq. (3) derived from Brug's equation [25];

$C_{o x}=\left[Q_{o x} R_{e}^{(1-n)}\right]^{\frac{1}{n}}$

Table 2

Electrochemical parameters obtained from the proposed EEC (statistically homogenous groups are indicated by the same letters).

\begin{tabular}{llll}
\hline Samples & $\mathrm{R}_{\mathrm{ox}}\left(\mathrm{M} \Omega . \mathrm{cm}^{2}\right)$ & $\mathrm{C}_{\mathrm{ox}}\left(\mu \mathrm{F} . \mathrm{cm}^{-2}\right)$ & $\mathrm{n}$ \\
\hline Ti-6Al-4V & $1.30 \pm 0.42^{\mathrm{a}}$ & $15.2 \pm 1.7^{\mathrm{b}}$ & $0.92 \pm 0.01^{\mathrm{d}}$ \\
cast Ti-12Nb & $0.65 \pm 0.05^{\mathrm{a}}$ & $25.4 \pm 4.1^{\mathrm{c}}$ & $0.92 \pm 0.01^{\mathrm{d}}$ \\
sintered Ti-12Nb & $0.69 \pm 0.27^{\mathrm{a}}$ & $17.0 \pm 2.1^{\mathrm{b}}$ & $0.94 \pm 0.01^{\mathrm{e}}$ \\
\hline
\end{tabular}

All alloys presented a one-time constant indicating a passive film in contact with the electrolyte. In the low-frequency range, very similar $|\mathrm{Z}|$ (impedance modulus) values were observed for the sintered Ti-12Nb and the Ti-6Al-4 V alloys, and it was higher than the values of the cast Ti-12Nb alloy. The increased phase angle values at the middle-frequency range for alloys were close to $-90^{\circ}$ showing the capacitive behavior of a compact passive oxide layer. The phase angle values of the sintered $\mathrm{Ti}-12 \mathrm{Nb}$ sample were higher in the medium frequency range whereas the phase angle values of both Ti-12Nb alloys were slightly lower than the Ti-6Al-4 V alloy in the low-frequency range. As can be seen in Table 1, the average $R_{o x}$ value of the Ti-6Al-4 V was higher than the values of the cast Ti-12Nb and the sintered Ti-12Nb alloys, however, the difference was not statistically significant. The $C_{o x}$ of Ti-6Al-4 V and sintered Ti-12Nb were similar and significantly lower than the values of cast Ti-12Nb $(p<0.05)$. Moreover, the cast Ti-12Nb and Ti-6Al- $4 \mathrm{~V}$ alloys presented the same $n$ values whereas the value was statistically higher on the sintered $\mathrm{Ti}-12 \mathrm{Nb}$ alloy.

\subsection{Tribocorrosion results}

\subsubsection{Continuous and intermittent tribocorrosion under OCP}

The evolution of OCP and coefficient of friction (COF) both for continuous and intermittent sliding are given in Fig. 4, together with the evolution of $R_{p}$ (obtained from LPR), and $k_{1}$ (calculated repassivation rate) for intermittent sliding. Before sliding, all alloys showed stable potential values because of the presence of a passive oxide film on alloy surfaces. When sliding started, an instant drop in OCP values was observed for all alloys indicating the partial or total destruction of the oxide film at the contact region. During sliding, all tested alloys presented relatively large OCP oscillations resulting from passivation/ repassivation actions during both continuous and intermittent sliding. After sliding, all alloys recovered their potentials close to the ones recorded before sliding, due to the repassivation of the worn areas. Regarding the COF evolution, all alloys presented a similar trend under continuous and intermittent sliding where the Ti-6Al- $4 \mathrm{~V}$ alloy showed statistically significant lower COF values while the other alloys presented very similar values. Also, non-destructive linear polarization tests were performed at $7 \mathrm{~min}$. after stopping each sliding cycle to study the influence of intermittency on the polarization resistance. The sintered Ti-12Nb presented higher average $R_{p}$ values than the other alloys, however, statistically, the difference was not significant between the tested groups. The repassivation rate after sliding was calculated according to Hanawa et al. [26] by using the following equation:

$\Delta E=k_{1} \log t+k_{2}$

where $\Delta E$ is the potential variation, $t(s)$ is the time after stopping sliding, $k_{1}$ is the slope and $k_{2}$ is a constant defined by the solution where the sliding took place. $k_{1}$ values demonstrating the repassivation rate are showed in Fig. 4. No statistically significant difference was found on 

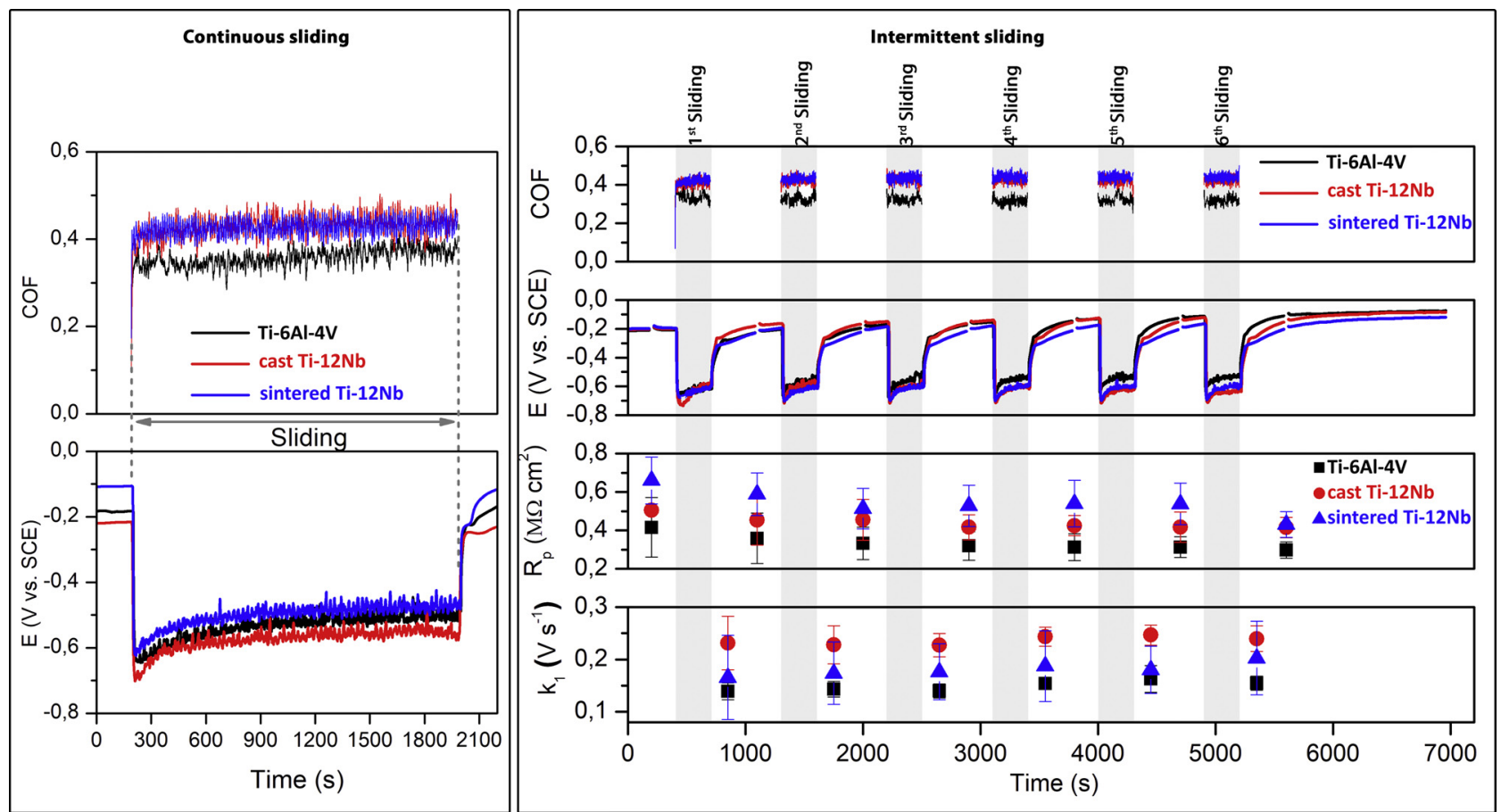

Fig. 4. a) Evolution of COF and potential during continuous sliding, b) evolution of COF, potential, $\mathrm{R}_{\mathrm{p}}$, and repassivation rate ( $\mathrm{k}_{1}$ ) during intermittent sliding.

the $k_{1}$ values between the sliding cycles. Regarding the comparison of the alloys, although the average values of the cast Ti-12Nb alloy were higher than the sintered Ti-12Nb and the Ti-6Al-4 V alloys, the difference between the groups was not statistically significant.

\subsubsection{Continuous tribocorrosion under anodic applied potential}

The current and COF evolution at $+0.5 \mathrm{~V}_{\mathrm{SCE}}$ anodic applied potential (AP), against an alumina ball, in saline solution are presented in Fig. 5. The current was stable and close to zero before sliding, in agreement with passive current $\left(i_{\text {pass }}\right)$ values from the potentiodynamic polarization curves (Fig. 3a). When sliding started, sudden current increases were caused by the mechanical destruction of the passive film (depassivation). This abrupt increase was observed for the Ti-6Al-4 V as soon as the sliding started, while an approx. $100 \mathrm{~s}$ delay was observed for the both Ti-12Nb alloys. During sliding, local current increments corresponded to decrements on COF values; were observed for all alloys, and it was more evident for the cast Ti-12Nb. Moreover, COF values at the AP condition were significantly higher than the ones recorded under the OCP condition $(p<0.05)$. The charge values obtained during sliding were calculated by $Q=\int_{0}^{t} I d t$ the equation as $0.022 \pm 0.007,0.026 \pm 0.010$, and $0.021 \pm 0.004 \mathrm{C}$ for the Ti-6Al$4 \mathrm{~V}$, cast Ti-12Nb, and sintered Ti-12Nb, respectively, where no statistically significant difference was found between the alloys.

\subsubsection{Wear morphology}

The wear morphologies after continuous and intermittent sliding at $\mathrm{OCP}$, as well, after continuous sliding at AP were analyzed by using secondary electron (SE) and backscattered electron (BSE) mode SEM to understand the wear mechanism (Fig. 6). Parallel sliding grooves, adhered oxidized particles, and plastic deformations were observed on all worn surfaces as usual wear surface features for Ti and its alloys. Regarding the testing conditions, while there were no clear differences in wear features between continuous and intermittent sliding at OCP, discontinuous tribolayer was observed on both Ti-12Nb alloys under AP condition as evidenced by the darker regions on the BSE images. Accordingly, existence of more tribolayer was observed on the BSE images of the cast Ti-12Nb alloy surfaces as compared to the sintered alloy for all testing conditions.

Fig. 7 shows the SE/SEM images and EDS spectra of wear scar on alumina ball surfaces taken from the wear scars after the tribocorrosion tests. Transferred material from samples to the alumina ball was confirmed by EDS spectra for all alloys in all tested conditions. Nevertheless, the transferred material at AP condition seemed to be drastically decreased while the intensity of the oxygen peaks was increased for all alloys.

\subsubsection{Wear loss}

Fig. 8 presents the wear volume loss after each testing condition.
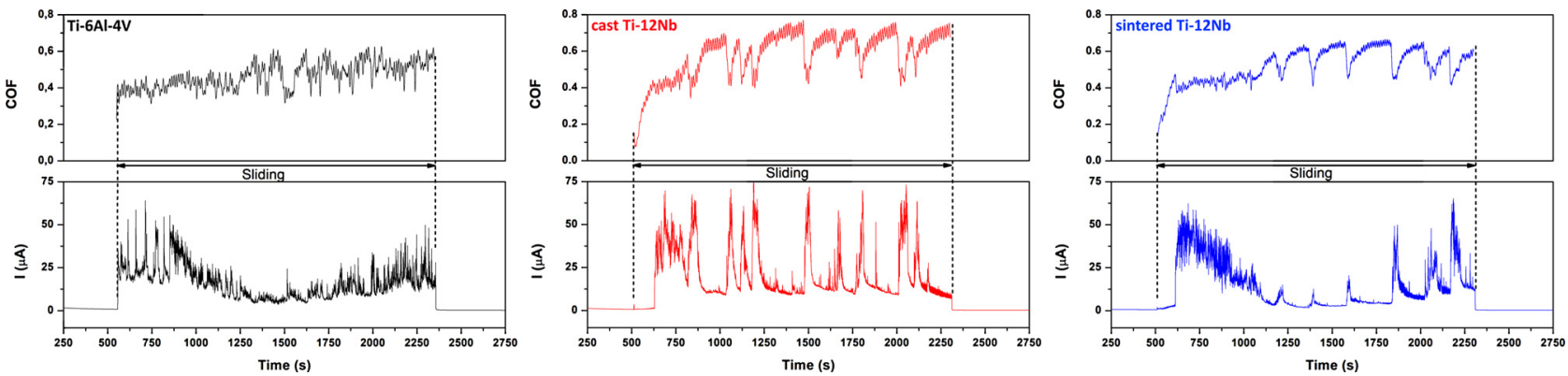

Fig. 5. The current evolution together with COF evolution for Ti-6Al-4 V, cast and sintered Ti-12Nb alloys under applied anodic potential. 

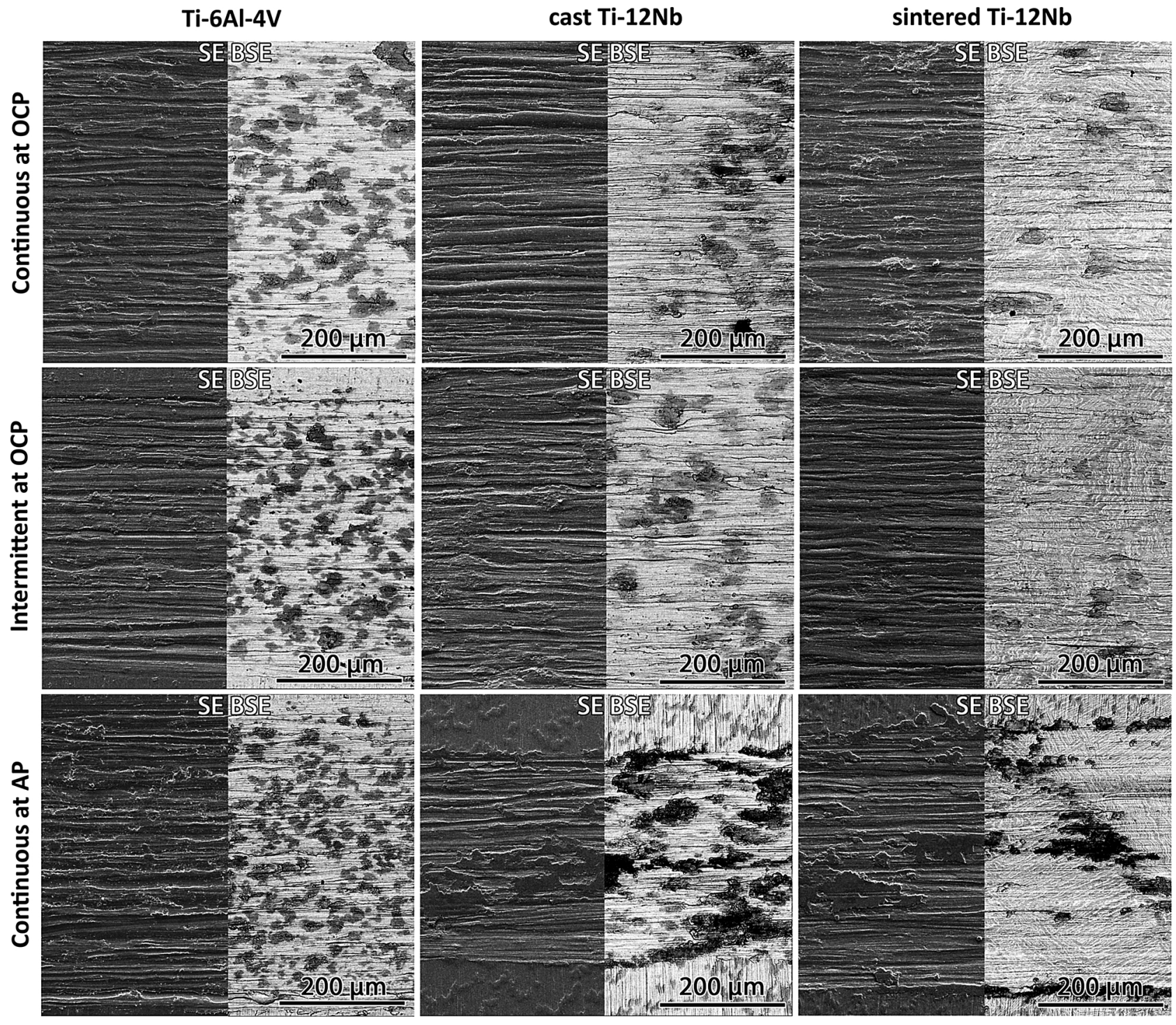

Fig. 6. SEM images of the worn alloy surfaces.

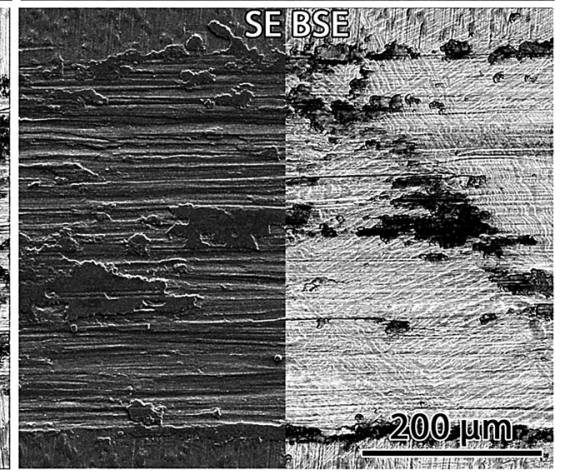

Wear volume loss on the Ti-6Al-4 V alloy was lower than the ones obtained for the both Ti-12Nb alloys, except for the AP condition $(p<0.05)$. Intermittency did not significantly affect the wear volume loss values of all alloys $(p<0.05)$. While wear volume loss of the Ti6Al-4 V was not significantly affected by the testing conditions, values of the both Ti-12Nb alloys tested at AP were significantly lower as compared to the other testing conditions $(p<0.05)$.

\section{Discussion}

The processing method influenced the corrosion behavior of Ti alloys in $9 \mathrm{~g} / \mathrm{l} \mathrm{NaCl}$ solution; this was attributed to the differences in the microstructures. Significantly nobler $E_{(i=0)}$ values (Fig. 3a) obtained for the sintered alloy indicated a lower tendency to corrosion $(p<0.05)$. Furthermore, significantly lower $C_{o x}$ values and $n_{o x}$ closer to 1 (Table 2) observed for the sintered alloy suggested a higher quality of the native oxide film $(p<0.05)$. The effect of the processing route on the corrosion behavior of various $\mathrm{Ti}$ alloys has been investigated in the literature. Within those, Toptan et al. [27] compared the corrosion and tribocorrosion behavior of Ti-6Al-4 $\mathrm{V}$ alloys processed by selective laser melting (SLM), hot pressing, and casting and forging, in saline $(9 \mathrm{~g} / \mathrm{l}$ $\mathrm{NaCl})$ solution. The authors reported that samples processed by SLM presented lower quality of passive film due to the lower amount of the $\beta$ phase and the presence of martensite $\left(\alpha^{\prime}\right)$ phase. Dalmau et al. [9] studied the corrosion behavior of Ti-6Al-4 V alloys in PBS electrolyte and reported higher corrosion resistance for the sintered alloy as compared to the rolled alloy due to its microstructure presenting smaller grain size, including pores, and having higher surface roughness. The relationship of microstructure and corrosion behavior on Ti$30 \mathrm{Nb}-\mathrm{Zr}$ alloy was investigated by Martins et al. [28]. The authors pointed that the alloy having a more uniform phase distribution presented better corrosion resistance due to the formation of a more homogeneous oxide film. Regarding phase volume fractions, Yang et al. [29] reported that the $\alpha$ phase had higher resistance to corrosion than the $\beta$ phase. Therefore, the relatively better corrosion behavior of the sintered Ti-12Nb compared to the cast alloy may be linked with its higher volume fraction of $\alpha$ phase and more uniform phase distribution along smaller grains that possibly led to a more homogeneous oxide film.

Tribocorrosion tests were performed both at OCP (continuous and intermittent) and at potentiostatic conditions by applying a potential corresponding to the passive region of the tested alloys. As reviewed by Cao and Mischler [30], tribocorrosion tests at OCP are closer to the simulation of a real implant system. But these tests do not provide information on the electrochemical kinetics. On the other hand, as pointed by López-Ortega et al. [31], tests performed at the anodic 

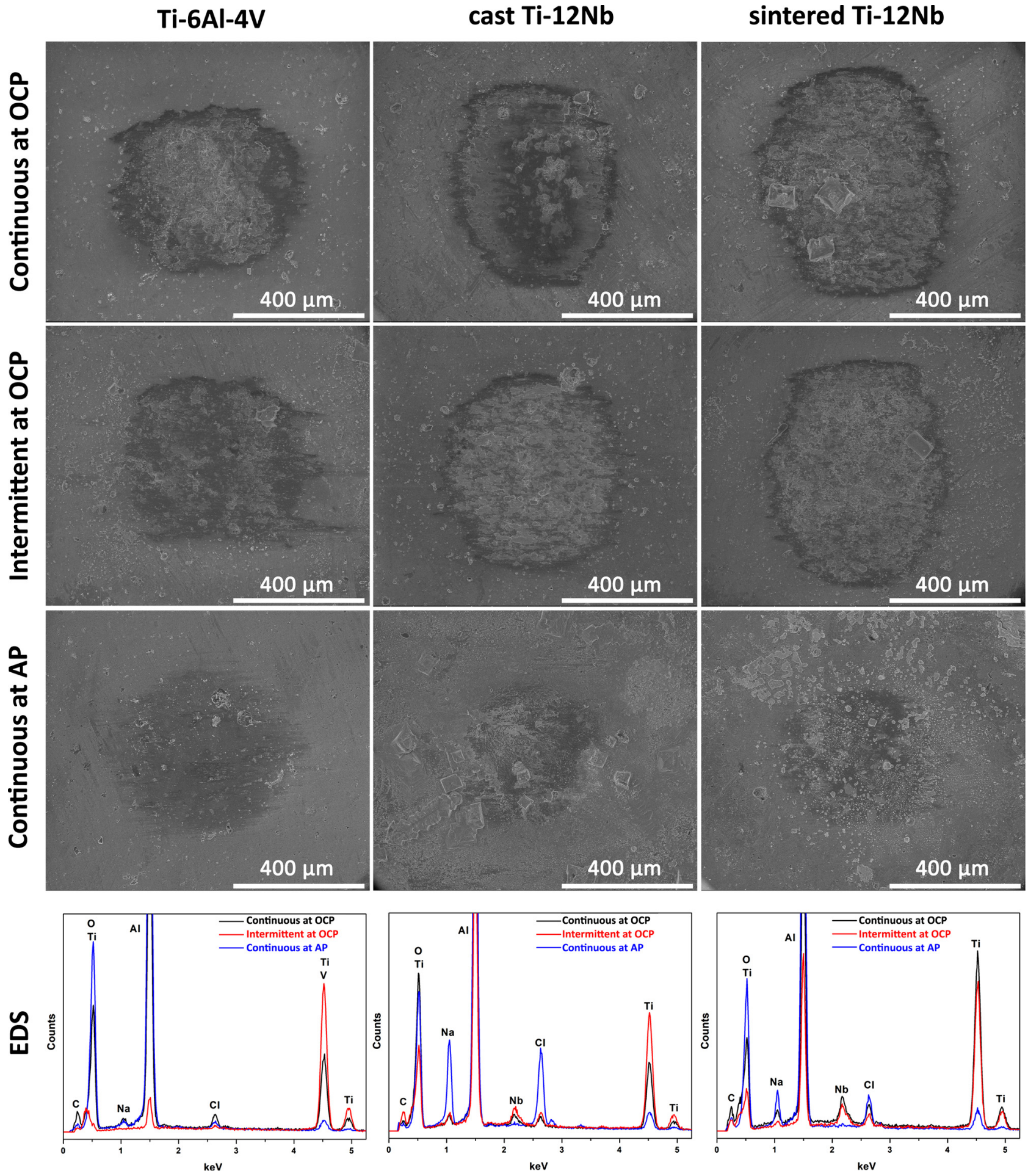

Fig. 7. SEM image of the wear scars on alumina balls and corresponding EDS spectra.

applied potential result in degradation by the combined effect of wear and corrosion, which provide information on electrochemical kinetics offering a better understanding to the prevailing wear mechanisms.

Several studies showed that Ti-6Al-4 V presents better wear resistance than the $\alpha+\beta$ Ti-15Nb [15], near $\beta$ Ti-13Nb-13Zr [16], $\beta$ Ti$12 \mathrm{Mo}-6 \mathrm{Zr}-2 \mathrm{Fe}$ [17], and $\beta$ Ti-29Nb-13Ta-4.6 Zr [18] mainly due to its higher hardness resulting from its microstructure. Under OCP conditions, the Ti-6Al-4 V alloy presented lower wear volume loss that may be linked to its higher hardness values compared to the Ti-12Nb alloys. However, among the Ti-12Nb alloys, although cast alloy has relatively lower hardness value, it exhibited lower wear volume loss that may be linked with the characteristics of the tribolayer generated during sliding. SEM observations of the worn surfaces suggested that the discontinuous tribolayer covered a larger area on wear tracks of the cast alloy, which may be connected with the lower quality of its oxide layer (evidenced by significantly higher $C_{o x}$ value from the EIS test) that requires further investigation. The total wear volume loss of both Ti$12 \mathrm{Nb}$ alloys in AP condition was significantly lower than that of the wear volume loss obtained at OCP condition $(p<0.05)$. It is known that applied potential can affect the material loss under tribocorrosion 


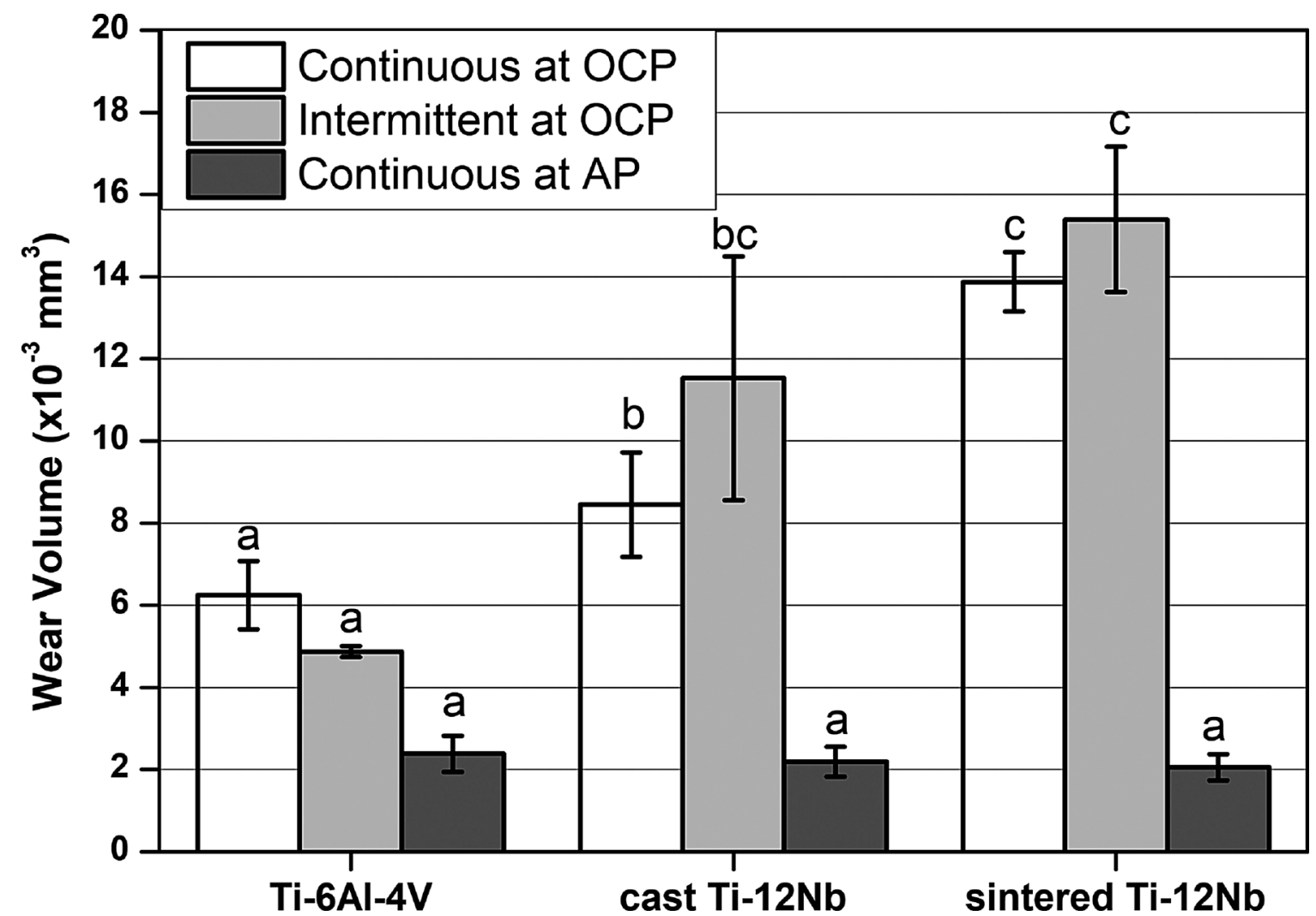

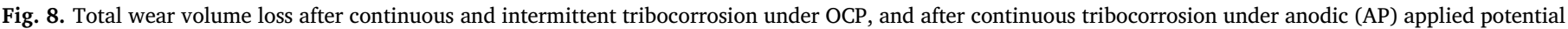
(statistically homogenous groups are indicated by the same letters).

[20]. On one hand, a lower amount of wear-enhanced corrosion is expected at passive domain (such as AP condition in the present study), compared to OCP domains, as a consequence of the continuous repassivation of damaged oxide film imposed by the potentiostat. On the other hand, a larger amount of corrosion-enhanced wear (in particular, mechanical wear of repassivated material) is expected at passive domain than in OCP conditions, due to the third body wear arising from the removed oxide particles whose formation was increased under applied potential [32-36]. In the case of Ti-12Nb alloys, the worn area covered by the discontinuous tribolayer was substantially increased under AP and it apparently played a protective role against tribocorrosion (Fig. 6). Some of the present authors had recently reported a similar behavior also for $\beta$ type Ti-40Nb alloy tested under continuous sliding at $+0.5 \mathrm{~V}_{\mathrm{SCE}}$ (passive region) in $9 \mathrm{~g} / \mathrm{l} \mathrm{NaCl}$ electrolyte, due to the formation of a tribolayer [37]. The elevated formation of the discontinuous tribolayer on the worn Ti- $12 \mathrm{Nb}$ alloy surfaces at AP condition may be influenced by the fast repassivation of $\mathrm{Nb}$ [1]. However, after reaching a certain thickness, this discontinuous layer may be removed by the counter-material resulting in a rapid increase in the current density values (Fig. 5).

Intermittent sliding tests enabled studying the mechanism of the regular removal and regrowth of surface oxide films through the sliding cycle followed by a pause time. There was no visible influence of intermittency on the wear track features, as well as on the evolution of $\mathrm{COF}, \mathrm{OCP}, R_{p}$, and $k_{1}$ values. The higher average $k_{1}$ values of the cast alloy may be linked with its passivation plateau that started to be formed at relatively lower potentials (Fig. 3a), though it needs further studies to reveal clearly the correlations. Finally, intermittency did not play a statistically significant difference on the wear volume loss for any alloy.

Although the degradation behavior of alloys was systematically studied, some limitations have been encountered. In order to have a better understanding to the corrosion mechanism, long-term corrosion behavior should be studied in more complex solutions and the released ions into the testing solution should to be quantified. Furthermore, future works should also take into consideration the effect of boneforming cells on the corrosion and tribocorrosion mechanisms.

\section{Conclusions}

The corrosion and tribocorrosion behavior of the Ti-12Nb alloy processed by different processing techniques (casting and $\mathrm{P} / \mathrm{M}$ ) was investigated in $9 \mathrm{~g} / 1 \mathrm{NaCl}$ at $37 \pm 2{ }^{\circ} \mathrm{C}$, in comparison with the commercial Ti-6Al-4 V alloy. Results revealed better overall degradation resistance for the commercial Ti-6Al-4 V alloy as compared to the both Ti-12Nb alloys. The corrosion behavior of the sintered Ti-12Nb alloy was better than the cast alloy; this could be attributed to its more uniform microstructure. Both Ti-12Nb alloys showed significantly lower wear volume loss at AP condition than in OCP conditions; this was attributed to the formation of discontinuous tribolayer, which was prevalently observed on the worn surfaces after AP tests. The intermittency did not affect significantly the wear volume loss in tested conditions.

\section{CRediT authorship contribution statement}

I. Çaha: Conceptualization, Methodology, Formal analysis, Investigation, Data curation, Writing - original draft, Visualization. A.C. Alves: Conceptualization, Formal analysis, Writing - review \& editing, Visualization. C. Chirico: Methodology, Investigation. S.A. Tsipas: Methodology, Investigation, Writing - review \& editing. I.R. Rodrigues: Methodology, Investigation. A.M.P. Pinto: Resources, Methodology. C.R. Grandini: Methodology, Investigation, Writing review \& editing. L.A. Rocha: Methodology, Investigation, Writing review \& editing. E. Gordo: Methodology, Investigation, Writing - review \& editing. F. Toptan: Conceptualization, Formal analysis, 
Visualization, Resources, Writing - review \& editing, Supervision, Project administration, Funding acquisition.

\section{Declaration of Competing Interest}

The authors declare that they have no known competing financial interests or personal relationships that could have appeared to influence the work reported in this paper.

\section{Acknowledgments}

This work was supported by FCT national funds, under the national support to R\&D units grant, through the reference project UIDB/04436/ 2020 and UIDP/04436/2020, together with M-ERA-NET/0001/2015, and co-supported by Brazilian agencies CNPq [grants \#308.204/2017-4 and \#125.954/2018-2] and FAPESP M-ERA-NET [grant \#2015/ 50.280-5], also by MINECO (Spain) through the program PCIN-2016123 and the Ramón y Cajal project RYC-2014-15014. I. Çaha is grateful for a PhD grant under the NORTE-08-5369-FSE-000012 project.

\section{References}

[1] M. Geetha, A.K. Singh, R. Asokamani, A.K. Gogia, Ti based biomaterials, the ultimate choice for orthopaedic implants - A review, Prog. Mater. Sci. 54 (2009) 397-425, https://doi.org/10.1016/j.pmatsci.2008.06.004.

[2] M. Niinomi, M. Nakai, Titanium-based biomaterials for preventing stress shielding between implant devices and bone, Int. J. Biomater. (2011) 1-10, https://doi.org/ $10.1155 / 2011 / 836587$.

[3] M.A. Gepreel, M. Niinomi, Biocompatibility of Ti-alloys for long-term implantation, J. Mech. Behav. Biomed. Mater. 20 (2013) 407-415, https://doi.org/10.1016/j. jmbbm.2012.11.014.

[4] S. Abdi, M.S. Khoshkhoo, O. Shuleshova, M. Bönisch, M. Calin, L. Schultz, J. Eckert, M.D. Baró, J. Sort, A. Gebert, Effect of Nb addition on microstructure evolution and nanomechanical properties of a glass-forming Ti-Zr-Si alloy, Intermetallics. 46 (2014) 156-163, https://doi.org/10.1016/j.intermet.2013.11.010.

[5] Y. Bai, Y. Deng, Y. Zheng, Y. Li, R. Zhang, Y. Lv, Q. Zhao, S. Wei, Characterization, corrosion behavior, cellular response and in vivo bone tissue compatibility of titanium-niobium alloy with low Young's modulus, Mater. Sci. Eng. C. 59 (2016) 565-576, https://doi.org/10.1016/j.msec.2015.10.062.

[6] H. Matsuno, A. Yokoyama, F. Watari, M. Uo, T. Kawasaki, Biocompatibility and osteogenesis of refractory metal implants, titanium, hafnium, niobium, tantalum and rhenium, Biomaterials. 22 (2001) 1253-1262, https://doi.org/10.1016/S01429612(00)00275-1.

[7] E. Y1lmaz, A. Gökçe, F. Findik, Ho.O. Gulsoy, Metallurgical properties and biomimetic HA deposition performance of Ti-Nb PIM alloys, J. Alloys. Compd. 746 (2018) 301-313, https://doi.org/10.1016/j.jallcom.2018.02.274.

[8] M. Geetha, U. Kamachi Mudali, A.K. Gogia, R. Asokamani, B. Raj, Influence of microstructure and alloying elements on corrosion behavior of Ti-13Nb-13Zr alloy, Corros. Sci. 46 (2004) 877-892, https://doi.org/10.1016/S0010-938X(03)00186-0.

[9] A. Dalmau, V. Guiñón Pina, F. Devesa, V. Amigó, A. Igual Muñoz, Influence of fabrication process on electrochemical and surface properties of Ti-6Al-4V alloy for medical applications, Electrochim. Acta 95 (2013) 102-111, https://doi.org/10. 1016/j.electacta.2013.01.155.

[10] P.A. Revell, The combined role of wear particles, macrophages and lymphocytes in the loosening of total joint prostheses, J. R. Soc. Interface 5 (2008) 1263-1278, https://doi.org/10.1098/rsif.2008.0142.

[11] M.K. Dimah, F. Devesa Albeza, V. Amigó Borrás, A. Igual Muñoz, Study of the biotribocorrosion behaviour of titanium biomedical alloys in simulated body fluids by electrochemical techniques, Wear. 294-295 (2012) 409-418, https://doi.org/ 10.1016/j.wear.2012.04.014.

[12] M.P. Licausi, A. Igual Muñoz, V. Amigó Borrás, Influence of the fabrication process and fluoride content on the tribocorrosion behaviour of Ti6Al4V biomedical alloy in artificial saliva, J. Mech. Behav. Biomed. Mater. 20 (2013) 137-148, https://doi. org/10.1016/j.jmbbm.2013.01.019.

[13] M.F. Semlitsch, H. Weber, R.M. Streicher, R. Schön, Joint replacement components made of hot-forged and surface-treated Ti-6Al-7Nb alloy, Biomaterials. 13 (1992) 781-788, https://doi.org/10.1016/0142-9612(92)90018-J.

[14] X. Yang, H. Pan, J. Zhang, H. Gao, B. Shu, Y. Gong, X. Zhu, Progress in mechanical properties of gradient structured metallic materials induced by surface mechanical attrition treatment, Mater. Trans. 60 (2019) 1543-1552, https://doi.org/10.2320/
matertrans.MF201911.

[15] I. Çaha, A.C. Alves, P.A.B. Kuroda, C.R. Grandini, A.M.P. Pinto, L.A. Rocha, F. Toptan, Degradation behavior of Ti-Nb alloys: corrosion behavior through 21 days of immersion and tribocorrosion behavior against alumina, Corros. Sci. 167 (2020) 108488, , https://doi.org/10.1016/j.corsci.2020.108488.

[16] I. Cvijović-Alagić, Z. Cvijović, S. Mitrović, V. Panić, M. Rakin, Wear and corrosion behaviour of Ti-13Nb-13Zr and Ti-6Al-4V alloys in simulated physiological solution, Corros. Sci. 53 (2011) 796-808, https://doi.org/10.1016/j.corsci.2010.11. 014.

[17] X. Yang, C.R. Hutchinson, Corrosion-wear of $\beta$-Ti alloy alloy TMZF (Ti-12Mo-6Zr$2 \mathrm{Fe}$ ) in simulated body fluid, Acta Biomater. 42 (2016) 429-439, https://doi.org/ 10.1016/j.actbio.2016.07.008.

[18] Y.S. Lee, M. Niinomi, M. Nakai, K. Narita, K. Cho, Predominant factor determining wear properties of $\beta$-type and $(\alpha+\beta)$-type titanium alloys in metal-to-metal contact for biomedical applications, J. Mech. Behav. Biomed. Mater. 41 (2015) 208-220, https://doi.org/10.1016/j.jmbbm.2014.10.005.

[19] C. Chirico, S. Tsipas, F. Toptan, E. Gordo, Development of Ti-Nb and Ti-Nb-Fe beta alloys from TiH2 powders, Powder Metall. 62 (2019) 44-53, https://doi.org/10. 1080/00325899.2018.1563953.

[20] P. Ponthiaux, F. Wenger, J. Pierre, Tribocorrosion: material behaviour under combined conditions of corrosion and mechanical loading, in: Corros, Resist., IntechOpen (2012), https://doi.org/10.5772/35634.

[21] P. Ponthiaux, R. Bayon, F. Wenger, J.-P. Celis, Testing Protocol for the Study of Biotribocorrosion, Woodhead Publishing Limited, 2013, https://doi.org/10.1533/ 9780857098603.3.372.

[22] G.W. Stachowiak, A.W. Batchelor, Engineering Tribology, (2000) http://www.ncbi. nlm.nih.gov/pubmed/22068761.

[23] Z. Doni, A.C. Alves, F. Toptan, J.R. Gomes, A. Ramalho, M. Buciumeanu, L. Palaghian, F.S. Silva, Dry sliding and tribocorrosion behaviour of hot pressed CoCrMo biomedical alloy as compared with the cast CoCrMo and Ti6Al4V alloys, Mater. Des. 52 (2013) 47-57, https://doi.org/10.1016/j.matdes.2013.05.032.

[24] S. Banumathy, R.K. Mandal, A.K. Singh, Phase transformation textures in hot-rolled binary Ti-Nb alloys, Metall. Mater. Trans. A Phys. Metall. Mater. Sci. 44 (2013) 2499-2511, https://doi.org/10.1007/s11661-013-1634-x.

[25] M.E. Orazem, B. Tribollet, Electrochemical Impedance Spectroscopy, (2008), https://doi.org/10.1002/9780470381588.

[26] T. Hanawa, K. Asami, K. Asaoka, Repassivation of titanium and surface oxide film regeneration in simulated bioliquid, J Biomed Mater Res1. 40 (1998) 530-538 doi:10.1002/(SICI)1097-4636(19980615)40:4 < 530::AID-JBM3 > 3.0.CO;2-.

[27] F. Toptan, A.C. Alves, Ó. Carvalho, F. Bartolomeu, A.M.P. Pinto, F. Silva, G. Miranda, Corrosion and tribocorrosion behaviour of Ti6Al4V produced by selective laser melting and hot pressing in comparison with the commercial alloy, J. Mater. Process. Technol. 266 (2019) 239-245, https://doi.org/10.1016/j. jmatprotec.2018.11.008.

[28] D.Q. Martins, W.R. Osório, M.E.P. Souza, R. Caram, A. Garcia, Effects of Zr content on microstructure and corrosion resistance of Ti-30Nb-Zr casting alloys for biomedical applications, Electrochim. Acta 53 (2008) 2809-2817, https://doi.org/10 1016/j.electacta.2007.10.060.

[29] Y. Yang, C. Xia, Z. Feng, X. Jiang, B. Pan, X. Zhang, M. Ma, R. Liu, Corrosion and passivation of annealed Ti-20Zr-6.5Al-4V alloy, Corros. Sci. 101 (2015) 56-65, https://doi.org/10.1016/j.corsci.2015.08.038.

[30] S. Cao, S. Mischler, Modeling tribocorrosion of passive metals - a review, Curr. Opin. Solid State Mater. Sci. (2018) 1-15, https://doi.org/10.1016/j.cossms.2018. 06.001.

[31] A. López-Ortega, J.L. Arana, R. Bayón, Tribocorrosion of passive materials: a review on test procedures and standards, Int. J. Corros. Scale Inhib. (2018) 24, https://doi. org/10.1155/2018/7345346.

[32] Y. Sun, V. Rana, Tribocorrosion behaviour of AISI 304 stainless steel in $0.5 \mathrm{M} \mathrm{NaCl}$ solution, Mater. Chem. Phys. 129 (2011) 138-147, https://doi.org/10.1016/j. matchemphys.2011.03.063.

[33] C. Jun, Corrosion wear characteristics of TC4, 316 stainless steel, and Monel K500 in artificial seawater, RSC Adv. 7 (2017) 23835-23845, https://doi.org/10.1039/ c7ra03065g.

[34] A. Igual Muñoz, L. Casabán Julián, Influence of electrochemical potential on the tribocorrosion behaviour of high carbon CoCrMo biomedical alloy in simulated body fluids by electrochemical impedance spectroscopy, Electrochim. Acta 55 (2010) 5428-5439, https://doi.org/10.1016/j.electacta.2010.04.093.

[35] P. Henry, J. Takadoum, P. Berçot, Tribocorrosion of 316L stainless steel and TA6V4 alloy in H2SO4 media, Corros. Sci. 51 (2009) 1308-1314, https://doi.org/10.1016/ j.corsci.2009.03.015.

[36] S. Barril, S. Mischler, D. Landolt, Electrochemical effects on the fretting corrosion behaviour of Ti6Al4V in $0.9 \%$ sodium chloride solution, Wear (2005) 282-291, https://doi.org/10.1016/j.wear.2004.12.012.

[37] I. Çaha, A. Alves, C. Chirico, A. Pinto, S. Tsipas, E. Gordo, F. Toptan, Corrosion and tribocorrosion behavior of Ti-40Nb and Ti-25Nb-5Fe alloys processed by powder metallurgy, Metall. Mater. Trans. A Phys. Metall. Mater. Sci. 51 (2020) 3256-3267, https://doi.org/10.1007/s11661-020-05757-6. 